\title{
Laparoscopic Central Bisectionectomy Including Resection of the Segment 7 Using the Extrahepatic Glissonean Approach and Hepatic Vein Guidance
}

\author{
Rawisak Chanwat, $\mathrm{MD}^{1}$, Tatsana Uthaithammarat, $\mathrm{MD}^{2}$, and Sar Thaithaworn, $\mathrm{MD}^{3}$ \\ ${ }^{1}$ Department of Surgery, National Cancer Institute, Bangkok, Thailand; ${ }^{2}$ Department of Surgery, Faculty of Medicine, \\ Chulalongkorn University, Bangkok, Thailand; ${ }^{3}$ Department of Surgery, Police General Hospital, Bangkok, Thailand
}

\begin{abstract}
Background. Certain variations in liver anatomy can aid in parenchymal-preserving hepatectomy. ${ }^{1,2}$ Inferior right hepatic vein (IRHV) is an accessory vein in the right side of liver draining segment $6{ }^{2}$ We present a case of 67-yearold man with HBV cirrhosis. One HCC in segment 7 abutting the right hepatic vein (RHV) and another large HCC in segment 8/4a were found. After two sessions of TACE, liver resection was scheduled. Resection of RHV was inevitable to get free margin. Fortunately, a significant IRHV was present, so we could preserve segment 6 . Central bisectionectomy with segment 7 resection using the Glissonean pedicle approach, and hepatic vein guided transection was planned. ${ }^{3}$
\end{abstract}

Methods. After placement of trocars, pneumoperitoneum was created. The main surgical steps were: (1) Right anterior Glissonean pedicle control; (2) Parenchymal transection along the umbilical fissure; (3) Transection of the right anterior portal pedicle, middle, and right hepatic vein; (4) Parenchymal transection between segments 5 and 6; and (5) Identification of IRHV and resection of segment 7.

Results. The operative time was $330 \mathrm{~min}$, and estimated blood loss was $80 \mathrm{~mL}$. The total intermittent inflow

Electronic supplementary material The online version of this article (https://doi.org/10.1245/s10434-020-08668-3) contains supplementary material, which is available to authorized users. occlusion time was $90 \mathrm{~min}$. The histopathologic diagnosis was well-differentiated HCC. The tumors size of segments 8 and 7 was $4 \mathrm{~cm}$ and $2.9 \mathrm{~cm}$, respectively. The resection margin was negative. The patient was discharged uneventfully on postoperative day 5 .

Conclusions. The preserved liver parenchyma after hepatectomy demands good vascular inflow and outflow. A large IRHV could be adequate outflow of segment 6 , allowing more distinct operations.

DISCLOSURES There are no conflicts of interest.

INFORMED CONSENT The patient in this study received an explanation of the procedure and provided informed consent. This study was approved by the institutional review board.

\section{REFERENCES}

1. Makuuchi M, Hasegawa H, Yamazaki S, Takayasu K. Four new hepatectomy procedures for resection of the right hepatic vein and preservation of the inferior right hepatic vein. Surg Gynecol Obstet. 1987;164(1):68-72.

2. Tani K, Shindoh J, Akamatsu N, et al. Venous drainage map of the liver for complex hepatobiliary surgery and liver transplantation. HPB. 18(12):1031-8.

3. Chanwat R. Useful maneuvers for precise laparoscopic liver resection. Asian J Endosc Surg. 2018;11:93-103.

Publisher's Note Springer Nature remains neutral with regard to jurisdictional claims in published maps and institutional affiliations.

(C) Society of Surgical Oncology 2020

First Received: 18 March 2020;

Published Online: 2 June 2020

R. Chanwat, MD

e-mail: mpub49@yahoo.com 